\title{
LITERATURA E CIBERESPAÇO: BLOGUE E ESCRITAS DE SI
}

\author{
LITERATURE AND CYBERSPACE: BLOG AND SELF-WRITING
}

\author{
Nincia Cecilia Ribas Borges Teixeira ${ }^{35}$
}

\begin{abstract}
RESUMO: O diálogo entre a literatura e outras esferas da mídia é crescente. Autoras paranaenses, por exemplo, utilizam o ciberespaço para publicar seus textos e escrevem para expressar suas ideias ou para contar a sua história. Ocorre, dessa forma, um deslocamento e uma reconfiguração dos modos de escrita. Carla Luma, Bárbara Lia e Deisi Perin, selecionadas para a pesquisa, utilizam blogues pessoais para publicarem seus escritos e marcam suas trajetórias por meio de práticas socioculturais. Para a pesquisa foram utilizados os pressupostos teóricos de Philippe Lejeune (1975) acerca da escrita sobre si, de Michel Pêcheux (1990) e Eni Orlandi (2001; 2002) sobre discurso e autoria, bem como as ideias de Paula Sibilia (2008) que tratam sobre identidades e Blog.
\end{abstract}

PALAVRAS-CHAVE: Blogue. Autoria feminina. Literatura Paranaense. Efeitos de sentido.

ABSTRACT: The dialogue between literature and other spheres of mass media is increasing. Female authors from the state of Paraná, for example, use the cyberspace to publish their texts and write to express their ideas or to tell their story. Thus, there is a displacement and a reconfiguration of writing modes. Carla Luma, Barbara Lia and Deisi Perin, selected for this paper, use personal blogs to publish their writings and mark their paths through sociocultural practices. For the research, the theoretical assumptions of Philippe Lejeune (1975) about Michel Pêcheux (1990) and Eni Orlandi's $(2001 ; 2002)$ writing on self and discourse and authoring, as well as Paula Sibilia's (2008) ideas on Identities and Blog, were used.

KEYWORDS: Blog. Female authorship. Literature of Paraná. Meaning effects.

\section{Escritas de si: entre discurso e literatura}

\begin{abstract}
Havia o diário, onde eu podia escrever minhas verdades, minhas inquietações, minhas aflições pessoais, minhas confissões, meus amores, e havia poesia, que era uma outra coisa, e que eu não entendia direito o que era. Até que começaram a se aproximar os dois, entendeu? (Ana Cristina César, Escritos no Rio, Brasiliense, 1993, p. 206)
\end{abstract}

O espaço da literatura, da criação literária e da leitura na perspectiva discursiva confere ao sujeito, em nossa cultura, um lugar especial e destacado. A arte de escrever na modernidade, segundo Luis Fernando Duarte, é uma criação solitária, que envolve a psicologia dos personagens e a psicologia do autor, axiada sobre o tema da "inspiração íntima", devendo brotar das profundezas do indivíduo-autor" (DUARTE, 1981, p.43). Envolve, ainda, uma linguagem própria ao sujeito criador, em um funcionamento que privilegia a polissemia e os efeitos de deslocamento. A arte de escrever, vigente culturalmente, além de ser uma prática solitária, é também da ordem da intimidade, pois revela na sua especificidade - o domínio da linguagem - o seu ancoramento ao primeiro termo da dicotomia indivíduo x sociedade, no âmbito da literatura. Nos domínios discursivos, a arte de escrever relaciona-se com a inscrição do sujeito em formações discursivas, que determinam o que ele pode/deve dizer, (PÊCHEUX, 1997, p. 160), apesar de para o sujeito parecer ser da ordem do individual, pela ilusão que ele tem de ser a origem do dizer e de esquecer-se de que "retomamos sentidos pré-existentes" (ORLANDI, 2002, p. 35). A

\footnotetext{
${ }^{35}$ Professora Associada do Departamento de Letras e do Programa Mestrado em Letras da Universidade Estadual do Centro-Oeste (Unicentro/PR).ninciaborgesteixeira@yahoo.com.br
} 
literatura constitui-se como texto e circula socialmente, convocando sujeitos à interpretação e, apesar de pertencer à ordem da criação, para ser compreendido, tem sempre um fundo de realidade, pois se consubstancia no/pelo mundo. É no texto que o desvio é valorizado como manifestação da individualidade, mesmo que esta individualidade se concretize por esquecimentos e ilusões. Orlandi (2002, p. 35) diz que "embora se realizem em nós, os sentidos apenas se representam como se originando em nós: eles são determinados pela maneira como nos inscrevemos na língua e na história e é por isso que significam e não pela nossa vontade".

Entretanto, uma vez valorizada e enquadrada como desvio, a literatura adquire legitimidade própria, que lhe confere plena liberdade de criação, e tudo se torna possível já que não possui responsabilidade social e pode, por isso mesmo e nestes limites, "revelar à sociedade sua loucura, propor questões, permitindo o prazer na dúvida". Como discurso do desvio por excelência, [...] a literatura pode sê-lo sob o preço de nunca se tornar o discurso da sociedade" (COSTA LIMA, 1972, p.65).

No que diz respeito ao escritor, a tensão entre o imaginário e o real sofre um rebatimento para o plano do "eu". Ainda, segundo Costa Lima (1984, p.228), "o imaginário tem relação direta com a possibilidade de ampliar o que chama de 'ângulo de refração' das experiências pessoais do escritor". Para o autor, essa é a expressão usada para contestar a noção de reduplicação especular, segundo a qual, as figuras compostas pelo escritor seriam meros reflexos ou projeções de seu eu.

Assim, ao mesmo tempo em que o imaginário permite a "transformação" do escritor em personagens que nada têm a ver com ele, tal transformação é alimentada pela refração de sua experiência pessoal (esta, vivida no plano da "realidade"), o ângulo de refração sendo o espaço no interior do qual se estabelece a tensão entre o eu imaginário e o eu "real". Desse modo, o "eu" do escritor na narrativa ficcional dissipa-se no espaço aberto pelo ângulo de refração, permitindo ao escritor inventar múltiplas possibilidades, imaginar-se, enfim, "um outro", que na verdade é a imagem dele mesmo, instaurando efeitos de movência do eu e a possibilidade de chorar pela morte de um personagem, como se estivesse sendo "possuído" por, ou se "metamorfoseando" em sua criação.

De tudo isso, depreende-se que a ficção, se questionada corretamente, fornece aspectos sociais que não são encontrados na historiografia oficial. Um dos fatores determinantes para esse acontecimento é o descompromisso da obra literária com a ordem da verdade, do real. Cabe ao estudioso da obra, então, identificar nela uma realidade ilusoriamente peculiar, pessoal e individual do autor, posto que se trata de transfigurar, mistificar, reconfigurar o específico de certa realidade. Mesmo assim, vale destacar, citando Pêcheux (1997), a interpelação ideológica e o atravessamento pelo inconsciente, fazendo com que a literatura, assim como outros textos, guarde a narrativa e sua característica de objeto construído de acordo com a ideologia de quem escreve, apagando o fato de que "quando nascemos os discursos já estão em processo e nós é que entramos nesse processo. [...] Isso não significa que não haja singularidade na maneira como a língua e a história nos afetam", mas que a língua e a história se realizam nos sujeitos como materialidade. Assim, a literatura está no campo do "vir a ser" e não do já realizado. O romancista irá se utilizar de seus personagens para expor suas ideias, sua percepção. Brockmeier (2005) assevera que uma das funções essenciais da narrativa como arte é, portanto, subjetivar o mundo.

Blanchot (1987) destaca que o mundo proposto pela literatura é autossuficiente, um mundo próprio, em que as suas bases não estão de modo algum subservientes ao mundo real, ao mundo do autor que a produziu, uma vez que a obra - a obra de arte, a obra literária - não é acabada nem inacabada. O espaço literário, por mais que seja semelhante ao espaço dos homens, é mundo de regras próprias, em que prevalece a não verdade, o não poder e o não saber, subsidiados pela ambiguidade: "Na literatura, a ambiguidade é como entregue aos seus 
excessos pelas facilidades que ela encontra, e esgotada pela extensão dos absurdos que pode cometer" (BLANCHOT, 1987, p.19). Nessa perspectiva, a literatura deixa de ser um modo de representação, perdendo a referência possível com o mundo real, para tornar-se apresentação de si mesma como um mundo possível e diversificado, pois cada escritor possui uma maneira diferenciada de nos apresentar esse mundo por meio da escrita.

$\mathrm{Na}$ perspectiva literária, "O espaço literário" é fatalmente aquele em que se dá a "morte" do escritor (como origem suposta de seu discurso), uma vez que uma ausência irremediável fala por meio dele. Esse anonimato da palavra conduziu Maurice Blanchot (1987) a conceber a experiência literária como uma dramaturgia da linguagem, da qual sua obra crítica e romanesca é espelho. Essa leitura filosófica permite pensar o projeto crítico blanchotiano como forma de retirar da literatura tudo o que não é ela (o autor e sua história, as relações de "gênero", estilo, língua, tudo que for relativo ao material linguístico da obra). "Escrever é quebrar o vínculo que une a palavra ao eu, quebrar a relação que, fazendo-me falar para "ti", dá-me a palavra no entendimento que essa palavra recebe de ti, porquanto ela te interpela, é a interpelação que começa em mim porque termina em ti. Escrever é romper esse elo. É, além disso, retirar a palavra do curso do mundo, desinvesti-la do que faz dela um poder qual, se eu falo, é o mundo que se fala".

No entanto, ao colocar- lhe um ponto final, o artista percebe que nada realizou, pois a obra, depois de feita, suprime seu criador, tem existência autônoma. Escrever uma obra é, nesse sentido, abdicar-se de si. A escrita literária não é resultado da vontade do autor, da sua intenção ou da sua sensibilidade. Pelo contrário, a dinâmica neutra da escrita conduz ao apagamento da figura do autor, ao anonimato necessário, à solidão essencial e ao estranhamento anti-lírico diante do mundo.

O texto autobiográfico não tem a função de narrar acontecimentos da ordem do vivido, posto que na prática narrativa o sujeito, sempre tomado como posição e inscrito em lugares, interpreta a si mesmo, mas essa interpretação não se liga ao intencional, tendo em vista a interpelação ideológica e o atravessamento pelo inconsciente. Assim, mesmo quando diz "eu", o sujeito que assume o lugar e a função de autor não fala exatamente de si mesmo, mas organiza a memória determinando o que faz sentido e o que ressoa como o já sabido, a partir de uma posição social, do lugar de escritor, que por entrar nessa ordem do discurso e por inscrever-se em uma Formação Discursiva que lhe permite dizer o que diz, fala da literatura, da política mundial, de viagens, das tormentas e, também, da sua vida.

Mesmo em se tratando de memória, o sujeito que ocupa a posição e exerce a função de autor, faz projeções imaginárias em torno de si mesmo, dos leitores e do tema que desenvolve, colocando-se no lugar deles. Segundo Pêcheux (1997a, p. 82), trata-se da projeção em que um sujeito A projeta um sujeito B e a partir dessa projeção encaminha seu discurso. Orlandi, nesse sentido, diz que

[...] segundo o mecanismo de antecipação, todo sujeito tem a capacidade de experimentar, ou melhor, de colocar-se no lugar em que o seu interlocutor "ouve" suas palavras. Ele antecipa-se assim a seu interlocutor quanto ao sentido que suas palavras produzem. Esse mecanismo regula a argumentação, de tal forma que o sujeito dirá de um modo, ou de outro, segundo o efeito que pensar produzir em seu ouvinte. (ORLANDI, 2002, p. 39)

Na perspectiva discursiva, o texto autobiográfico remete ao equívoco de que o sujeitoautor narra objetivamente fatos relacionados à sua vida e que os dizeres e os saberes são da ordem da realidade. Segundo Venturini (2009, p. 121), "[...] para minimizar os efeitos desse equívoco há que estabelecer diferenças entre sujeito e eu e entre real e realidade". O sujeito, por sua vez, resulta da inscrição do sujeito a Formações Discursivas (FD), a lugares que são determinantes no que ele diz e, no caso do texto autobiográfico, ao conteúdo do que é dito. 
A possibilidade de aliar o discursivo ao literário deve-se ao fato de que, no âmbito da literatura, a escrita de si é vista como um discurso e, nesse discurso, a função-autor é de organizar as experiências fragmentárias do eu, dando sentido ao que aparece na memória (individual e coletiva) de forma caótica. Trata-se, portanto, de um fazer-acreditar naquilo que está sendo contado: não o que aconteceu, mas o que significou. Por essa razão, as escritas de si trazem valores e representações ligadas ao inconsciente de sujeitos de uma sociedade e até mesmo de um país. Fritzen (2003) afirma que o gênero autobiográfico passa a ser como uma relação de aprendizagem, que a experiência narrada do outro nos sugere.

Sendo assim, o ponto de interseção entre o real e o ficcional é o escritor, assumindo a função-autor, organizando o mundo ficcional. É ele quem vai catalisar os anseios e características daquela sociedade. É uma arte que instiga o sujeito-leitor e, por esse motivo, é transformadora. De acordo Orlandi (2001, p. 65), pela função-autor é que se constrói a textualidade, que, no que tange ao discurso, "produz um efeito imaginário de unidade", como se o texto tivesse começo, meio, não-contradição e fim. Pela função-autor, o sujeito se pensa a "origem" do dizer, assumindo a responsabilidade pelo que diz. Nesse sentido, mesmo que o texto seja o mesmo, o autor continue assumindo a mesma posição, a cada leitura o texto é outro, o sentidos variam, de acordo com a inscrição do sujeito em formações discursivas que determinam o dizer.

A autobiografia, ao invés de suscitar a dissipação do eu em múltiplos "outros", parece, ao contrário, reafirmar sua unidade. Nas palavras de Philippe Lejeune (1975), o que caracteriza a autobiografia é a identidade entre narrador e autor, expressada através do pacto autobiográfico estabelecido com o leitor, espécie de declaração do tipo "isto é autobiografia". Lejeune $(1975$, p. 14) procura inferir que "a autobiografia é principalmente uma narrativa, com perspectiva retrospectiva e cujo assunto tratado é a vida individual; e implica necessariamente a identidade entre autor, narrador e personagem".

A identificação entre autor, narrador e personagem é condição essencial de uma autobiografia, consubstanciada no pacto autobiográfico: a identidade entre o nome exposto na capa e na folha de rosto (um nome que equivale a uma assinatura) e o nome que o narrador se dá como personagem principal, acrescida na maioria das vezes da indicação, na capa, na folha de rosto, nas orelhas e na contracapa, de que se trata de uma autobiografia. O pacto autobiográfico se dá quando a identidade entre autor, narrador e personagem é assumida e tornada explícita pelo autor, ao contrário do "pacto romanesco", declaração de negação daquela identidade e atestado do caráter de ficção. É por isso, também, que uma autobiografia nunca pode ser anônima, porquanto lhe faltaria assim o nome do autor, daquele que atualiza o pacto.

Atualmente, basta acessar a internet que nos deparamos com inúmeras páginas e nelas muitas mulheres publicam seus escritos sobre si. Escrita que, assim como a escrita de outros tempos, também expressa modos de ser e estar no mundo, de vivenciar e significar o corpo. Autoras paranaenses, muitas vezes, utilizam o ciberespaço para publicar seus textos, escrevem para expressar suas ideias, contar a sua história. Ocorre, dessa forma, um deslocamento e reconfiguração dos modos de escrita. As escritoras selecionadas para a pesquisa utilizam blogues pessoais para publicarem seus escritos.

Os blogues são páginas on line, pessoais, dinâmicas, interativas que podem tratar de variados assuntos. Há blogues nos quais são publicadas notícias, comentários esportivos, poesias, receitas culinárias, contos. Outros trazem fatos da vida pessoal de quem ali escreve seus pensamentos, seu cotidiano, seus (des)amores, pois o sujeito também pode utilizar esse espaço para falar da sua intimidade, para falar de si. Os blogues, assim como outros modos de escrita na internet, portam rastros da comunicação "face-a-face", em que um sujeito "fala" e outro/s "responde/m" (no caso dos blogs, através de comentários), guardando suas particularidades de tempo e velocidade, uma vez que a internet possibilita que o que é escrito 
de um determinado computador ou de um Iphone, por exemplo, possa ser acessado pelos/as demais usuários/as da rede, que podem estar espalhados por todos os cantos do mundo, ou a poucos metros de distância.

Por se constituir em um dos espaços em que algumas pessoas falam de suas dores, seus amores, suas misérias, do seu dia de trabalho, como lidam com o corpo, dos pequenos detalhes de seu cotidiano para o/a provável leitor/a da página, faz-se possível apontar o caráter confessional pelo qual a escrita em blogues é dotada. Entretanto, concordo com Paula Sibilia (2008, p.71) quando refere que mencionar apenas o caráter confessional dos blogues é "[...] uma explicação possível, embora parcial, pois deixa sem elucidar algumas de suas especificidades mais significativas". No caso das escritoras paranaenses, observa-se que o blogue é um canal para a divulgação da escrita literária. Para a pesquisa foram selecionadas as autoras Carla Luma, Bárbara Lia e Deisi Perin.

\section{Escritas de autoria feminina: cenas paranaenses}

Os últimos anos têm sido marcados por uma eclosão nas instâncias sociais, políticas, econômicas e culturais que se especializaram em decretar o fim dos pressupostos da sociedade tradicional, dentre eles, o esfacelamento do patriarcalismo. Sabe-se que o discurso considerado universal, aquele que se pretende patriarcal, logocêntrico, ou seja, dominado pelo homem, traz em seu cerne essa marca de restrição com relação à mulher.

A produção da escrita de autoria feminina, especialmente a literária, conhece de perto esse fato e busca, de certa forma, denunciar a ideologia patriarcal que ainda ronda o cotidiano de muitas mulheres. Além dessa denúncia, espera fazer emergir a identidade da mulher do século XXI na literatura.

A literatura de autoria feminina passa, atualmente, por um processo de conscientização. Por alguns anos, a contar das primeiras décadas do século $\mathrm{XX}$, a mulher escrevia, muitas vezes, com ressentimento, procurando destruir a simbologia masculina que a reprimia. Atualmente, há o registro do início de uma conscientização do sexo masculino à presença de um novo estilo de mulher na sociedade. Esse fenômeno é idêntico, tanto para a literatura feita pelos homens, como por aquela feita pelas mulheres. Entretanto, há, na literatura de autoria feminina, a busca pelo "[...] feminino autêntico, pressentido para além dos destroços da 'imagem tradicional da mulher', patente na crise em processo em nossos tempos." (COELHO, 1989, p.04).

A evolução da consciência crítica da mulher em relação a si mesma e ao espaçotempo onde/em que vive, fundamenta-se na visão sociológica sobre as relações de poder na sociedade, pois a tentativa de se sobrepor à soberania masculina fez reforçar as hierarquias no campo da arte. Superar a imagem tradicional da mulher e recuperar a voz exigiram das escritoras a concentração sobre si mesma e sobre o conjunto, propondo a construção de uma literatura do ser humano, sem discriminações, num universo sem privilégios.

A reflexão sobre a escrita de autoria feminina remete ao processo histórico que a produz, como fenômeno cultural, bem como as relações de poder e de confronto de interesses que ocorrem na sociedade e que irão influenciar em seu significado. Dessa forma, acredita-se que é preciso refletir sobre o passado para que se possa compreender o presente.

$\mathrm{Na}$ formação da sociedade paranaense, podem-se visualizar traços culturais variados e distintos que se mesclaram e deixaram marcas no comportamento provinciano e conservador de seu povo, especialmente, quando se refere à conduta feminina. $\mathrm{O}$ comportamento da mulher paranaense, conforme o lugar que ocupa dentro dessa sociedade, é permeado de regras e traços de uma sociedade agrária, que exige um comportamento recatado e doméstico próprio dos costumes da vida nas fazendas, regras que estão enraizadas não só na classe dominante, 
mas, também, atuam na orientação do comportamento das famílias de classe alta e média, as quais exigem que a mulher tenha uma "boa formação", incluindo nessa formação escolas religiosas e casamento com bons partidos. Entretanto, sob o manto da permissividade ou do respeito a todas as expressões individuais e coletivas, está um Paraná austero, conservador em suas práticas políticas e sociais, um estado vigilante de seu código patriarcal. Talvez, por toda essa atmosfera, recrudesçam e se perpetuem as regras patriarcais que regiam $o$ comportamento da mulher no século passado.

Apesar das conquistas e de significarem mais de $44,6 \%$ do mercado de trabalho no Paraná, as mulheres continuam enfrentando obstáculos para a ascensão profissional. $\mathrm{O}$ rendimento das mulheres é $42 \%$ inferior ao dos homens, segundo dados do IBGE. Apesar de constantes discussões acerca da posição da mulher no mercado de trabalho e de sua ascensão ser mais ponderada, ela tem começado a destacar-se em atividades que antes eram consideradas masculinas, como na Construção Civil, em que a remuneração média das mulheres foi de $2,3 \%$ maior que a dos homens. As trabalhadoras ainda recebem menos porque se inserem profissionalmente em ocupações de menor remuneração, produtividade e prestígio social. Os segmentos que mais absorvem força de trabalho feminina são os mais desvalorizados no mercado de trabalho e os que tendem a propiciar remunerações mínimas, como o setor de saúde, educação e serviços pessoais, principalmente o emprego doméstico. A entrada de qualquer bandeira feminista foi sempre dificultada por essa mentalidade hegemônica, misto de ideologia agrário-burguesa com a regência da Igreja.

A exclusão histórica da autoria feminina no campo institucional da literatura, em especial no Paraná, foi resultado de práticas culturais que privilegiaram a enunciação do sujeito dominante da cultura, o sujeito masculino. As causas do silêncio envolvendo a história literária da mulher encontram-se nos preconceitos que sempre cercearam a escrita feminina. Os críticos literários do passado, em sua maioria homens de letras, sempre tiveram uma atuação determinante na configuração dos cânones nacionais, através de trabalhos acadêmicos.

Na primeira metade do século XX, muitas mulheres ainda se deparavam com inúmeras barreiras do ideal de feminilidade vigente, que procurava conjugar os papéis de mãe, esposa e dona de casa; as ideologias de controle social na qual tinha destaque o papel da mulher; as dificuldades para seguir com seus estudos ou consolidarem-se em certas profissões. Destacase com um dos primeiros movimentos organizados por mulheres no Paraná, o Centro Paranaense Feminino de Cultura (CPFC), fundado na cidade de Curitiba em 1933, do qual um conjunto de associações de mulheres que, combinando ações culturais e educativas com o trabalho filantrópico, contribuíram para a ampliação dos espaços de atuação femininos na primeira metade do século XX. As centristas, como eram chamadas suas participantes, pautavam-se nos ideais do maternalismo, do higienismo e da puericultura em voga naquele período, defendiam a função social da maternidade e a valorização das mulheres por esse papel, bem como o direito à educação, ao trabalho e à autonomia feminina, ainda que não se declarassem feministas. Assim, não se deve deixar de lado a importância dessas associações femininas na primeira metade do século XX no Brasil, valorizando as práticas e as estratégias de mulheres que, majoritariamente advindas de classes média e alta, dedicaram-se a esse tipo de atividade como forma de agir sobre o mundo em que viviam.

Segundo Rose Zanardo (2010), a sindicalização das mulheres, um marco no movimento de mulheres do Paraná, introduziu a discussão do cotidiano do trabalho, da desvalorização do salário, da segregação ocupacional, da ausência de infraestrutura de assistência à trabalhadora gestante, da violência no local de trabalho e também das práticas sindicais que as excluem de uma participação mais ativa nos postos de decisão.

A década de 1980 foi marcada pela reconstrução das instâncias da democracia liberal: reorganização partidária, eleições para os diversos níveis, reelaboração da Constituição do 
país, eleições presidenciais etc. A questão da democracia, presente na constituição dos movimentos sociais, colocou na relação desses com o Estado as suas reivindicações. As políticas públicas passam à agenda dos movimentos de mulheres no Paraná.

A literatura feita por mulheres, juntamente com a discussão sobre a negritude e a literatura homoerótica, é fenômeno significativo dos últimos anos do século XX e insere-se na discussão do multiculturalismo. A produção de autoria de mulheres sempre foi excluída, por várias razões, dentre elas o puro preconceito de uma sociedade atrelada a valores patriarcais que reservava à mulher o papel de esposa e mãe. Assim, sua produção sempre foi avaliada como deficitária em relação à norma de realização estética vista sob o ponto de vista masculino. Para Peggy Sharpe (1997), é comum nas Literaturas Coloniais omitir ou subrepresentar relatos advindos da voz feminina, só em iniciativas mais atuais é que ocorrem discussões em torno da identidade nacional advinda de várias vozes, inclusive a feminina.

O que se observa no Paraná é o número muito restrito de escritoras. Mesmo que não se considere somente o número de autoras apenas nascidas, mas também radicadas no estado, o cenário continua o mesmo. Se considerar coletâneas como as organizadas por Luiz Ruffato, 25 Mulheres Que Estão Fazendo a Nova Literatura Brasileira (2004) e + 30 Mulheres que Estão Fazendo a Nova Literatura Brasileira (2005), ambas publicadas pela Record, somando as autoras de uma e de outra, são 55 mulheres. Dessas, apenas duas são do Paraná: Luci Collin e Regina Iorio. O equivalente a mais ou menos 3\% do total.

Diante disso, pode-se dizer que os estados com maior poder econômico promovem uma maior visibilidade das escritoras. Quanto menor a inserção da mulher na sociedade - que se dá, no meu ponto de vista, basicamente por conta da educação - menor o número de mulheres pensando a sociedade. Há ainda outra questão: a de que a colonização do interior do Paraná - com a produção de riquezas, através da cafeicultura - se deu muito recentemente e que, numa sociedade agrária, a educação da mulher sempre foi colocada em segundo plano. Assim, de certa forma pode-se justificar que a falta de escritoras esteja justamente na falta de espaço regular para publicação e na falta de remuneração para o ofício. Luci Collin, escritora paranaense, perguntada se teve de encarar alguma dificuldade específica por ser mulher, responde que "por ser mulher, não; por ser paranaense, sim". Para publicar seus livros, precisou vencer o eixo Rio - São Paulo.

\subsection{Carla Luma: inquietações femininas}

Creio no Universo como numa abstração,/porque
penso nele. Mas não o vejo/ porque pensar é
compreender... (Carla Luma)

Carla Luma nasceu em Jacarezinho no Paraná, escreve no blogue http://carlaluma.blogspot.com.br/, que se constitui como uma possibilidade de tornar público seus textos e escritos. O blogue dá lugar a experimentações. Por sua estrutura ser aberta, convida o usuário à criação de páginas e de textos variados, à interação com outros. Segundo Maria Rita Kehl (2007), só no século XX é que a fala das mulheres migrou do espaço privado para o público e passou a produzir diferença. Os blogues, no final do século XX e início do XXI, alargaram em muito a possibilidade de escrita de si, assim como sua visibilidade e circulação.

Sua escrita procura desmanchar a manutenção da visão de mundo "masculina", vigente na maioria das sociedades ocidentais modernas, ao mesmo tempo em que delineia e limita o "espaço" feminino, contribuindo, desta forma, para a construção da subjetividade das mulheres: 
Volume 13 - Número 1 - mai/jul de 2018

\begin{abstract}
Acontece é que cansei. Acontece é que eu não presto. Acontece é que eu jamais conseguiria meter um par de chifres em Federico: um cara tão perfeito, um gentleman, e, ao mesmo tempo, eu não consigo me satisfazer comendo do mesmo todos os dias, pode ser lagosta, camarão, feijoada, o manjar que se serve aos deuses no monte Olimpo... Eu não consigo. Estava ficando triste, melancólica, beirando a depressão. Mandei Federico pastar e, desde então, considero-me definitivamente curada. (LUMA, 2010)
\end{abstract}

As inquietações femininas em busca por uma identidade própria é o discurso predominante nos minicontos de Carla Luma, que busca romper com as funções atribuídas à mulher ao longo do tempo e revelando a sua necessidade em buscar autonomia e espaço dentro desse mundo até então descrito pelo homem. No conto, Federico, a personagem principal, retrata o papel da mulher que se submete às normas sociais, mas deseja transgredir, encontrando-se entre a vontade de violar e o cumprimento das normas, na qual não pode comandar suas ações devido à constante obediência às condições e modelos machistas. Dividida entre o "lado de cá" que representa as normas, e o "lado de lá", espaço da liberdade em que a protagonista tende a se autoafirmar, como retrata o fragmento abaixo:

Entretanto, conheci Federico quando eu já me considerava livre deste perigo. O cara entrou na minha vida como o furacão Katrina em Nova Orleans: avassaladoramente. É mentira. Não foi boa a comparação, mas gostei da imagem e não vou retirar. Na realidade ele chegou de mansinho e me conquistou trazendo-me flores, presentes, chocolates - sou doidinha por chocolate, principalmente os absurdamente amargos como se pudesse ler pensamentos, suprindo, desta forma, a figura do pai ideal. (LUMA, 2010).

A escrita de Carla Luma suplanta o estigma da fragilidade, desqualifica paradigmas de certa forma cristalizados em nossa cultura, desconstrói o estereótipo da "Amélia, a mulher de verdade"-registro de uma idealização social; ou da "mulher de cama e mesa" (ABREU, 1999. p. 131) e constitui efeito de verdade à medida que traz elementos do mundo, ligados ao real, tais como furacão Katrina, em Nova Orleans.

Eu não chorei. Sorri cinicamente, como se tranquilizada pelo anticlímax que se coaduna perfeitamente com a índole deste adorável covarde que, contudo, neste dia dos namorados, me trouxe flores, chocolates, uma garrafa de vinho e um livro com a Obra Poética Completa de Federico Garcia Lorca (LUMA, 2010)

A narrativa de Luma instaura o efeito de sentido de contestação de valores, deslocando os sentidos cristalizados acerca da mulher não só dentro da ordem social e política discriminatória, mas, também, e, sobretudo, no interior de uma ordem simbólica, em que a própria linguagem é um instrumento de opressão. Como foi insistentemente sublinhado por Roland Barthes, a língua encarrega-se de marcar a diferença sexual e social, mantendo, por um lado, separados os gêneros feminino e masculino, pelo outro "a servidão e o poder" (BARTHES, 2004 p. 15).

2.2 Bárbara Lia: escrita do não-lugar

Quando era menina descobri que o significado de Bárbara Lia é - Estrangeira de olhos tristes e cansados. Faz sentido. Sempre convivi com esta sensação de não-lugar. (LIA, 2011)

Bárbara Lia é professora de História e escritora, nasceu em Assaí - PR e vive em Curitiba. Publicou os livros: O sorriso de Leonardo (2004), Noir (2006), O sal das rosas 
(2007), A última chuva (2007) e Constelação de Ossos (2010). Bárbara Lia escreve em seu Blogue Chapar as Borboletas (http://chaparaasborboletas.blogspot.com.br/).

A escrita revela os amores e as dores da escritora, além de possibilitar que o mundo seja reinventado por meio de suas leituras e diálogos, indissociáveis, de todo modo, de suas identificações ideológicas, passionais e de sua busca constante pelo ideal humanista, segundo Marcio Claudino (2011). É comum, em sua obra, estabelecer diálogos com outros escritores e artistas como Fernando Pessoa, Dalton Trevisan, João Guimarães Rosa, Bertolt Brecht, Clube da Esquina, Tunai e Elis Regina, Raduan Nassar.

É visível em seus textos vestígios de um sujeito que, por meio da escrita e não de seu corpo, habita vários espaços (muitas vezes simultaneamente). Nesses espaços, ganha acesso a diferentes realidades, assumindo identidades e características diferenciadas, ou seja, pode construir diferentes narrativas (verídicas ou não, sinceras ou não, anônimas ou não) a respeito de si mesmo. Como se observa no miniconto "Pariabiru":

Peabiru é o meu refúgio mágico. Minha Pasárgada. Éden antigo. A felicidade andava colada ao meu ombro direito quando eu vivia ali. Eu vivi ali dos cinco aos dezesseis anos. [...] A cidade com seus costumes, a vida rígida. Bateu este banzo, este texto que alguém pode até dizer - piegas - mas, encontrei toda gente neste tal de Facebook; Na comunidade com o nome da cidade, que alguém comparou com Paris, preciso saber quem para dar o devido crédito. No final, todos os que passaram a infância e adolescência lá sabem que lá é uma cidade Luz, nossa Meca, nosso lugar... (LIA, 2011)

Nicolaci-da-Costa (2005) apresenta alguns fatores que interferem nesse jeito de reescrever/interpretar o mundo por meio de marcas comuns na pós-modernidade: a geração de novos espaços de vida, as alterações de amplo alcance nos estilos de agir, de viver e de ser dos homens e mulheres que lhes foram contemporâneos, observando ainda a proliferação de vocábulos que expressam novos interesses, novas necessidades, novas formas de vida, novos relacionamentos, novos conflitos. Matos (2007) assevera que:

Os efeitos perceptíveis dos "deslocamentos", ocasionados pela globalização,
produzem uma permanente re(construção) das identidades. Liquidifica-se o tempo, o
lugar, o real, o imaginário, as culturas, gerando novas formas de sociabilização,
novas relações no mundo do trabalho e no lazer. Esses deslocamentos influenciam
ainda a des(construção) do "mundo imaginário" e do "mundo real". Sabemos que o
sistema conhecido nos dias de hoje como globalização teve seu início muito antes,
desde as primeiras navegações. Mas esse movimento é recriado, principalmente com
o desenvolvimento das tecnologias (MATOS, 2007, p. 17).

Observa-se que Lia, em sua escrita, interpreta suas experiências em épocas e contextos determinados e, ao mesmo tempo, passa a agir de acordo com os significados construídos. É uma mulher em busca de sua identidade, e esta é de tal importância que vai iniciar seu próprio processo de individualização. É por meio dessa ruptura com o espaço/memória que emergem suas várias identidades:

O que você gostaria de ser se não fosse poeta?/Correr riscos e flanar acima de abismos, sem ser poeta?/Ressuscito um dos primeiros pensamentos de quando era menina: - Quero ser correspondente de guerra. [...] Quando você era criança, tinha mais medo de palhaço ou do Papai Noel? Palhaço. [...] Gosto de me libertar. Não creio em modelito perfeito para lançar livros... Cada poeta é um universo inteiro e suas adjacências, suas roupas são estrelas e os sapatos estradas e mar... (LIA, 2011)

Bárbara Lia, de forma consciente ou não, faz uma travessia pelo universo masculino. Mas, sua escritura se torna autônoma: emerge a voz feminina que vai se construindo da 
memória e das vivências pessoais, do sentimento e da escolha rigorosa das palavras ao narrar a sua realidade, o seu cotidiano. Adensa-se o texto, eliminando, gradativamente, o supérfluo, os exageros lacrimejantes, as lamentações. A escritora é sujeito da sua produção, em uma literatura que representa identidades femininas, que deixa de ser o Outro do masculino e passa a ser...ego:

Um patchwork mineiro dentro de mim [...]E água memorável/ Labirintos de Rosa: Meu pai plantou-me em Minas .Sem mar.Sem José.Sem amor.Minha herança: Sertões.Sonetos . Canções. Meu nome é uma montanha Minha sombra uma memória. Plantada naquela esquina (LIA, 2010).

2.3 Deise Perin: multiplicidade e efemeridade

\author{
Meu lugar \\ é em lugar algum \\ Não caibo nos espaços \\ nem navego no fluxo (Deise Perin, 2012)
}

A curitibana Deise Perin (Deise Giacomazzi Silva) escreve no Blogue Pó\&teias, (http://poeteias.blogspot.com.br/search/label/deisi\%20perin). Sua escrita é feita por meio de uma linguagem simples e se utiliza de espaços cotidianos para expressar temas banais, tipicamente pós-modernos. A era pós-moderna muda comportamentos dos sujeitos, que são repletos de contradições, seguem várias direções e se utilizam de várias máscaras sociais. Isso se deve ao fato de o homem na contemporaneidade ter de lidar com várias esferas ao mesmo tempo e estar cercado de muita informação. "A massa pós-moderna é atomizada, fragmentada, excitada pelas mensagens que lhes são destinadas segundo seus interesses individuais: o sujeito converte-se num terminal de informação, e num terminal isolado de outros terminais." (NAZARIO, 2005, p.58).

Meu lugar é em lugar algum. Não caibo nos espaços.Nem navego no fluxo.Visto tamanho único. Camadas de polimento escondem minha cor. Sorvo ácido e veneno cruzo as pernas delicadamente. Curvo-me. Rasgo as vestes, mas sempre sobra um trapo de culpa. (PERIN, 2010).

O sujeito que emerge da escrita de Perin é portador de múltiplas identidades, demonstrando como essa mulher atual lida com as questões da sexualidade, relações de afetividade e como traça para si múltiplas identidades. $\mathrm{O}$ fato de assumir vários papéis ao mesmo tempo, ser esposa, dona de casa, mãe, profissional, gera toda uma cobrança por parte da sociedade que exige demais das mulheres. Dessa forma, elas muitas vezes sentem-se sobrecarregadas com as novas relações que passaram a estabelecer com os homens a partir das mudanças sociais e, ainda, restam vestígios de culpa.

No poema "Efemeridade": "Espera e descansa. Os degraus da vida ensinam... Não se pode deixar de subir, nem sequer retroceder. A vida é bela! Tanto quanto o humor. Realidades à parte. Felicidade é efêmera flor." (PERIN, 2010), o próprio processo de identificação, pelo qual projetamos em nossas identidades, torna-se provisório, estabelece-se a identidade como uma '[...] celebração móvel': formada e transformada continuamente em relação às formas pelas quais somos representados ou interpelados nos sistemas culturais que nos rodeiam" (HALL, 1998, pp.12-13). Essa multiplicidade dos sistemas de significação e representação cultural gera uma concepção de identidade muito mais perturbadora e provisória, levando o sujeito pós-moderno a questionar seu lugar no cenário contemporâneo e suas representações de identidade. 


\section{Conclusão}

O Blogue é um espaço que permite as experimentações, sua estrutura aberta, com um espaço vazio, favorece a criação e efeitos de sentidos diferenciados Na narrativa de Luma, Lia e Perin, os efeitos de sentido manifestam-se pelos finais múltiplos, enredos labirínticos, arbitrariedade, descontinuidade. Os blogues, ao mesmo tempo em que permitem a escrita para as mulheres e a circulação desses escritores, facilitam a divulgação de posicionamentos, assumindo, por vezes, uma função política para os sujeitos femininos e, por meio deles, esses sujeitos contam, partilham e reivindicam uma visibilidade, um determinado espaço.

$\mathrm{Na}$ literatura paranaense de autoria feminina, ressoam discursos cada vez mais conscientes de sua situação de alteridade, sinalizando que a mulher não permite mais que a definam como a metade instável e antagônica da sociedade. No imaginário masculino atual, ela é ainda e antes de tudo a outra, o não-eu, muito mais do que a parceira. Este estranhamento se exprime nos sistemas simbólicos e de representação cotidiana da realidade, por meio das manifestações artísticas, como a literatura, por exemplo, agora em um novo suporte: o blogue.

A escrita de autoria feminina lança sobre o espaço da pós-modernidade olhares transgressores que levam a situar questões de gênero. Carla Luma, Bárbara Lia e Deise Perin escrevem na tentativa de (re)construírem a identidade da mulher, a partir da focalização da mulher escritora. O que se observa que, nesse sentido, são tecidas várias identidades femininas. A mulher "escrita" na literatura dessas paranaenses não se detém apenas em seres submissos, vítimas da opressão que foi imputada às mulheres durante séculos, visto que as autoras se recusam a levantar bandeiras do feminismo ou mesmo escrever como "mulherzinha".

Ao contrário, o sujeito da escritura das autoras analisadas são projeções de mulheres reais, que falam de si, sofrem, vivem. Destaca-se, também, o estilhaçamento da identidade, por rejeitar as hierarquias discriminadoras, a escrita acaba por não distinguir verdade e ficção, passado e presente, significativo e irrelevante.

É nesse contexto de mudanças de mentalidades, de novas subjetividades, de novos espaços de produção de saberes e poéticas várias que se situam as escrituras das paranaenses, que revelam a historio(grafia) das mulheres, cujas escrituras mostram-se capazes de inaugurar, parafraseando Adélia Prado, "reinos e linguagens".

\section{REFERÊNCIAS}

BLANCHOT, Maurice. O Espaço Literário. Rio de Janeiro, Rocco. 1987.

BARTHES, Roland. Aula. Cultrix: São Paulo, 2004.

BROCKMEIER, Jens; HARRE, Rom. Narrativa: problemas e promessas de um paradigma alternativo. Psicol. Reflex. Crit., Porto Alegre, v. 16, n. 3, 2003. Disponível em:

http://www.scielo.br/scielo.php?script=sci_arttext\&pid=S0102-

79722003000300011\&lng=pt\&nrm=iso. Acesso em: 22 de setembro de 2107.

CLAUDINO, Marcio. “O Sal das Rosas” Disponível em:

$<$ http://www.saldaterraluzdomundo.net/Livros_Lan\%C3\%A7amentos_sal_das_rosas.htm.>

Acesso em: 2/06/2012.

COSTA LIMA (Org.) Teoria da literatura em suas fontes. 2 ed. rev. e ampl. Rio de Janeiro, Francisco Alves, 1983.

DUARTE, Luiz Fernando. "A construção social da memória moderna". In: Três ensaios

sobre pessoa e modernidade. Boletim do Museu Nacional. Rio de Janeiro, p.28-54, 1981.

FRITZEN, Celdon. Histórias de vida em entrevistas sociolinguísticas: memórias e oralidade. Rev. Ciências Humanas, Criciúma, v.8, n.2, p.25-28, jul/dez. 2003. 
HALL, S.. A identidade cultural na pós modernidade. Tradução de Tomaz Tadeu da Silva e Guacira Lopes Louro: Rio de Janeiro: DP\&A, 1998.

Kehl M. R. (2007). "O que pode uma mulher”. O Estado de São Paulo, 30 dez. Disponível em : <http://www.estadao.com.br/noticias/suplementos,o-que-pode-uma-mulher,102473,0.htm>. Acesso em: 14/06/2012.

KUBOTA, Marilia. http://micropolis.blogspot.com.br/2006/04/onde-esto-as-mulheres.html. Acesso em: 2/06/2012.

LEJEUNE, Philippe. Le pacte autobio graphique. Paris, Seuil, 1975.

LIA, Bárbara. http://chaparaasborboletas.blogspot.com.br/ Acesso em: 14 jun. de 2012.

LUMA, Carla. http://carlaluma Análise de Discurso.blogspot.com.br/2010/04/federico.html. Acesso: 30/05/2012.

MATOS, M.C.R. "O acaso do discurso, o discurso do acaso: práticas de escrita de si nos blogs”. Dissertação (Mestrado) em Letras. Universidade Vale do Rio Verde de Três Corações. Minas Gerais, 2007. Orientador: Prof ${ }^{\mathrm{a}}$. Dr ${ }^{\mathrm{a}}$. Beatriz Maria Eckert-Hoff.

MUZART, Zahidé L. (Org.) Escritoras Brasileiras do Século XIX. 2 ed. Revisada.

Florianópolis: Editora Mulheres, 2000. Vol. 1

NAZARIO, Luiz. "Viagens Imaginárias". In: NAZARIO, Luiz (Org.). A Cidade Imaginária. São Paulo: Perspectiva, 2005.

NICOLACI-DA-COSTA, A. M. Primeiros contornos de uma nova "configuração psíquica". In: Cadernos CEDES - Antropologia e Educação - Interfaces do Ensino e da Pesquisa. Unicamp, Campinas/SP, v.25, n.65, 2005, p. 71-85.

ORLANDI, E. P. Formulação e circulação dos sentidos. Campinas, SP: Pontes Ed., 2001. Análise de Discurso: princípios e procedimentos. 4.ed. Campinas, SP: Pontes, 2002.

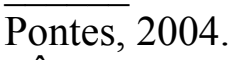
Interpretação: autoria, leitura e efeitos do trabalho simbólico. Campinas, SP:

PÊCHEUX, Michel. Por uma análise automática do discurso: uma introdução à obra de Michel Pêcheux. GADET, Françoise (Org.) Trad. de Bethania Mariani (et.al.) 3 ed. Campinas, SP: Unicamp, 1997a.

. Semântica e discurso: uma crítica à afirmação do óbvio. 3.ed. Trad. de Eni Orlandi et al. Campinas: Editora da UNICAMP, 1997.

PERIN, Deise. http://poeteias.blogspot.com.br/ Acesso em: 07/06/2012.

SIBILIA, Paula. O Show do Eu - A intimidade como espetáculo. Rio de Janeiro: Nova Fronteira, 2008.

VENTURINI, Maria Cleci: Imaginário urbano: espaço de rememoração/comemoração. Passo Fundo, Editora da UPF, 2009.

ZANARDO, Rose. "As Mulheres e o Feminismo". Disponível em:

$\mathrm{http}$ ://observatoriodamulher.org.br/site/index.php?option=com_content\&task=view\&id=2229 \&Itemid=3. Acesso em: 30 mai. 